\title{
The Study of Stress Conditions on Growth and Proteome of Raoultella Planticola: A New Emerging Pathogen
}

\author{
Zeynab Hajian \\ Islamic Azad University-Lahijan Branch \\ Mohammad Faezi Ghasemi ( $\square$ faezi_m@yahoo.com ) \\ Islamic Azad University of Lahijan https://orcid.org/0000-0003-2188-176X \\ Fatemeh(Elham) Alikhani \\ Islamic Azad University-Lahijan Branch
}

\section{Research Article}

Keywords: Raoultella planticola PTCC 1598, Stress conditions, Proteomics, Two-dimensional gel electrophoresis, Mass spectrometry

Posted Date: February 26th, 2021

DOI: https://doi.org/10.21203/rs.3.rs-246226/v1

License: (c) (i) This work is licensed under a Creative Commons Attribution 4.0 International License. Read Full License

Version of Record: A version of this preprint was published at Archives of Microbiology on April 12th, 2021. See the published version at https://doi.org/10.1007/s00203-021-02312-8. 


\section{Abstract}

All bacteria can survive and adapt to different stresses such as fluctuations in temperature, $\mathrm{pH}$ oxidative, and osmotic pressure occurring in their surrounding environments. This study aims to evaluate the effects of a variety of stress conditions on the growth, and proteome of Raoultella planticola PTCC 1598. R. planticola cells were exposed to different values of temperatures, sodium chloride, $\mathrm{pH}$, and hydrogen peroxide stresses. Amongst the stress conditions, oxidative stress upon exposure to hydrogen peroxide $\left(\mathrm{H}_{2} \mathrm{O}_{2}\right)$ at 4000 ppm concentration was selected for proteomics analysis in detail. Approximately 1400 spots were identified in two-dimensional gel electrophoresis (2-DE). Among the identified spots, 85 spots were repeatable using 2D-Platinum software and eye confirmation and, nine protein spots were differentially expressed. Among nine proteins, six proteins identified successfully with a MASCOT score greater than 40 ( $p<0.05)$ were 2, 3-dihydroxybenzoate-2, 3-dehydrogenase (oxidoreductase family), Dgalactose-binding periplasmic protein, uridine phosphorylase (glycosyltransferases), uridine phosphorylase, a single peptide match to cysteine-binding periplasmic protein, and NADP(H) nitroreductase. All identified proteins showed decreased level expression. Based on the obtained results, we concluded that hydrogen peroxide as an antiseptic compound could affect cell growth and proteomics of R.planticola. So, we recommend using an antiseptic solution containing $\mathrm{H}_{2} \mathrm{O}_{2}$ to prevent the spread of R.planticola as a new emerging pathogen.

\section{Introduction}

Raoultella planticola is a gram-negative, non-motile, aerobic bacillus that was first introduced by Bagley et al. 1981(Bagley et al., 1981). R.planticula previously classified as Klebsiella planticula and Klebsiella trevisanii, first was combined into one species, i.e., K.planticula, based on DNA-DNA homology in 1986. Then it was reclassified as Raoultella sp. based on 16S rRNA and rpoB gene sequencing results in 2001. Some characteristics such as the utilization of L-sorbose as a carbon source and the growth ability at 10 Centigrade are hallmarks of the genus Raoultella. The new genus includes the three species, Raoultella planticola, Raoultella ornithinolytica, and Raoultella terrigena(Fager \& Yurteri-Kaplan, 2019; Westerveld et al., 2017; Young \& Gibson, 1969).

R. planticolahas been considered as a nonclinical, aquatic, botanical, and soil organism. But nowadays it is considered as an emerging pathogen that causes some cases of human infections, including bacteremia, soft tissue infection(O'Connell et al., 2010), pancreatitis (Niedergethmann et al., 2007), and urinary tract infection(Olson et al., 2013). Also, other disorders such as prostate, conjunctiva, and gallbladder have recently been reported by $R$. planticola.

R. planticola hasthe ability to convert histidine to histamine and able to produce scombroid poisoning upon consumption of poorly prepared seafood(Lam \& Salit, 2014).

Different environmental stress conditions reduce bacterial cell viability and put them at risk. Acute stress requires an immediate and specific response to maximize cell survival (Bartholomäus et al., 2016). Actually, there are stress response pathways in bacteria which, dynamically monitor cellular status, and mediate adaptive changes by alteration the proteome, largely accomplished by remodeling at transcriptional and protein degradation levels (Guo \& Gross, 2014).

Proteomics analysis has been widely used in different basic and applied research and its analysis provides important information about changes in the synthesis, degradation, post-translation modification, and interactions among proteins. One of the most important aspects of proteomics is to study the expression levels and characterization of proteins in cells when we expose them to different stress conditions (Daware et al., 2012).

Hypoxia, UV radiation, and visible light changes across the day-night cycle are representative of oxidative stresses. Recently the impact of human activity on the environment, the toxic effects of man-made compounds also induced oxidative stresses in all organisms (Siauciunaite et al., 2019). Reactive Oxygen Species (ROS) (including peroxides (e.g., $\left.\mathrm{H}_{2} \mathrm{O}_{2}\right)$, superoxide $\left(\mathrm{O}_{2}\right)$, hydroxyl radicals $(\mathrm{OH})$, and singlet oxygen $\left(\mathrm{O}_{2}\right)$ are controlled by a balance between pro-oxidant and antioxidant elements. When increased levels of ROS are not disputed by increases of the antioxidant activity or reducing equivalents, a cell endures an oxidative stress state. Increasing the concentrations of ROS represent a potential source of damage for many macromolecules due to the induction of single and double-stranded DNA breaks, and irreversible denaturation of proteins through oxidation and carbonylation of arginine, proline, lysine, and threonine residues (Hayyan et al., 2016; Nathan \& Ding, 2010). Among the ROS factors affecting bacteria, oxidative stress using oxidizing compounds such as $\mathrm{H}_{2} \mathrm{O}_{2}$ as a disinfectant is important. Also, hydrogen peroxide is used to treat inflammation of the gums, disinfect (drinking) water and, combat excessive microbial growth in water systems and cooling towers (McDonnell, 2009). There are cellular mechanisms including enzymatic as well as non-enzymatic processes to counteract oxidative stress. One of them is the role of glutathione in its reduced state (GSH). Glutathione serves as an antioxidant in plants, animals, fungi, and also in some bacteria. It neutralizes ROS by directly donating a reduced equivalent $\left(\mathrm{H}^{++} \mathrm{e}^{-}\right)$. Another conserved antioxidant mechanism is based on the quick redirecting of carbohydrate flux from glycolysis to the pentose phosphate pathway(PPP) via inhibiting the activity of glycolytic enzymes such as GAPDH (glyceraldehyde-3-phosphate dehydrogenase). The PPP pathway then has the role of regulating cellular NADPH levels that help as the fuel for the antioxidant system. Also, a key adaptation for surviving the harmful effects is DNA repair mechanisms such as base excision repair, (BER) (Siauciunaite et al., 2019). Also, the gene expression control mechanisms plays important role in bacteria surviving at elevated ROS levels. For instance, in E.coli SoxRS regulon activates upon exposure to oxidative stress by $\mathrm{H}_{2} \mathrm{O}_{2}$ (Baez \& Shiloach, 2013). 
In Staphylococcus epidermidis, a new oxidation-sensing regulator, AbfR (aggregation and biofilm formation regulator) has been identified in response to oxidative stress-mediated by $\mathrm{H}_{2} \mathrm{O}_{2}$ (Liu et al., 2013). Recently, the effects of $\mathrm{pH}$, temperature, $\mathrm{NaCl}$ concentration, and heat resistances were studied on $R$. ornithinolytica and $R$. terrigena isolated from a seafood processing plant in Thiland (Tantasuttikul \& Mahakarnchanakul, 2019).

But to the best of our knowledge, there is little information regarding the effects of stress conditions on R.planticola as a newly emerging infectious bacterium. In this study, the effect of different stress conditions was evaluated on the growth of $R$. planticola PTCC 1598. Amongst the stress conditions, Hydrogen peroxide $\left(\mathrm{H}_{2} \mathrm{O}_{2}\right)$ at a concentration of was selected for proteome study of $R$. planticola PTCC 1598 .

\section{Materials And Methods}

\section{Bacterial strain, media, and growth conditions}

All media and materials used in this study obtained from (Merck Co. Darmstadt, Germany). The strain R. planticola PTCC 1598 was obtained from Persian Type Culture Collection (PTCC, Tehran, Iran). For primary culture, the lyophilized vial of $R$. planticola PTCC 1598 was streaked on nutrient agar (NA) and incubated at $37^{\circ} \mathrm{C}$ for $24 \mathrm{~h}$. For growth curve determination, an initial population of $4.5 \pm 0.5$ log $\mathrm{CFU} / \mathrm{mL}$ at $37^{\circ} \mathrm{C}$ was inoculated in nutrient broth (NB) medium. Samples were taken at intervals of $2 \mathrm{~h}$ and counted using spiral plating (Spiral Biotech model Autoplate 4000, USA) on NA medium in duplicate until the bacterial growth had reached the stationary phase by $20 \mathrm{~h}$.

\section{Condition used for different stresses}

For evaluating stress conditions, a single colony of $R$. planticola PTCC 1598 grown on nutrient agar (NA) was inoculated in nutrient broth (NB) medium. The optical density of growth was measured at $600 \mathrm{~nm}$ until the cells reach to mid-log phase $\left(O D_{600}=0.4-0.5\right)$. Then cells were harvested by centrifugation at $7,000 \mathrm{~g}$ at $4^{\circ} \mathrm{C}$ for $30 \mathrm{~min}$. The harvested cells were washed three times in $5 \mathrm{ml}$ of phosphate buffer (PB) and resuspend in $10 \mathrm{ml}$ of pre-chilled $\left(4^{\circ} \mathrm{C}\right) 0.1 \mathrm{M}$ phosphate buffer $(\mathrm{PB})$ and kept in a refrigerator.

For stress treatments, $R$. planticola PTCC 1598 cells in pre-chilled phosphate buffer were grown in nutrient broth to reach to mid-log phase $\left(\mathrm{OD}_{600}=0.4-\right.$ $0.5)$. For osmotic stress, cells were transferred into nutrient broth containing sodium chloride ( $\mathrm{NaCl})$ at $0.0 \%$ (control), $2 \%, 4 \%, 6 \%, 8 \%$ and $10 \%(\mathrm{w} / \mathrm{v})$. For oxidative stress, $R$. planticola PTCC 1598 cells were treated at concentrations of 500, 1000, 2000, 4000, 8000, and 16000 (ppm) of hydrogen peroxide $\left(\mathrm{H}_{2} \mathrm{O}_{2}\right)$. For acidic and alkaline stresses, Hydrochloric acid $(\mathrm{HCl}, 0.1 \mathrm{M})$ and Sodium Hydroxide $(\mathrm{NaOH}, 0.1 \mathrm{M})$ were used for adjusting the desired $\mathrm{pH}$. Nutrient broth containing $\mathrm{pH}$ values of $3,4,5,6,7,8,9$, and 12 were inoculated by $R$. planticola PTCC 1598 cells. The bacterial cell suspension was heat-stressed by inoculation into a fresh nutrient broth at temperatures of $45,55,65,75,85$, and $100{ }^{\circ} \mathrm{C}$. Then, the cells were centrifuged at $7000 \mathrm{rpm}$ for $30 \mathrm{~min}$ at $4^{\circ} \mathrm{C}$. Cell pellets were resuspended in 50 microliters of nutrient broth and inoculated in $100 \mathrm{~mL}-\mathrm{Erlenmeyer}$ containing $25 \mathrm{ml}$ fresh medium. For growth curve determination, incubation was performed at $37^{\circ} \mathrm{C}$ for $24 \mathrm{~h}$. Samples were taken at intervals of $2 \mathrm{~h}$, and survival curves were presented by plotting the logarithm of survival cell as log CFU/mL, using spiral plating (Spiral Biotech model Autoplate 4000 ,

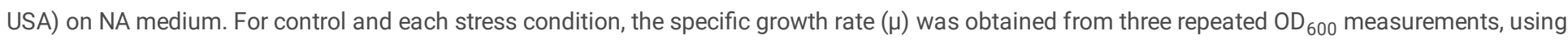
the time points of 4 as the initial point and $16 \mathrm{~h}$ as the final point of the exponential phase, all cultures continued for 24 hours. Specific growth rate ( $\mu$ ) and doubling time(td) were determined as described by Guerrero Montero et al. 2019 using the following equations (1 and 2):

$$
\text { 1) } \mu=\frac{\left(\ln X_{2}-\ln X_{1}\right)}{\Delta t}
$$

where $X_{1}$ and $X_{2}$ are the absorbance values measured at $600 \mathrm{~nm}$ at $4 \mathrm{~h}$ and $16 \mathrm{~h}$, respectively. Doubling time for the exponentially growing cultures was calculated as (Montero et al., 2019):

$$
\text { 2) } t_{d}=\frac{\ln 2}{\mu}
$$

\section{Sample preparation for 2-DE and protein extraction from $R$. planticola cells}

R. planticolacells were grown in nutrient broth until reaching to mid-log phase in two conditions including treatment with $\mathrm{H}_{2} \mathrm{O}_{2}$ at 4000 concentration and control. Then, cells were harvested by centrifugation at $7,000 \mathrm{~g}$ at $4^{\circ} \mathrm{C}$ for $30 \mathrm{~min}$. The harvested cells were washed three times with phosphate buffer (PB) and transferred into $1 \mathrm{~mL}$ Eppendorf tubes, kept at $-80^{\circ} \mathrm{C}$ for further use. For protein extraction, the cells in Eppendorf tubes were thawed and, grown in $75 \mathrm{ml}$ nutrient broth medium then harvested by centrifuging at $10000 \times \mathrm{g}$ at $4^{\circ} \mathrm{C}$ for 10 min. The pellets were washed twice with distilled water and resuspended in lysis buffer containing7 mol l-1 urea (Merck, Germany), 2 mol I-1 $^{-1}$ Thiourea (Merck, Germany),40 mmol $\mathrm{I}^{-1}$ Tris, $4 \% \mathrm{CHAPS}^{-}$ $0.2 \%\left(\mathrm{w} / \mathrm{v}\right.$ ) Biolyte 4/7 ampholyte (Bio-Rad Laboratories, Hercules, CA), and $50 \mathrm{mmol}^{-1} \mathrm{DTT}, 100 \mu \mathrm{l}$ of $1 \%$ ( $/ \mathrm{v}$ ) protease inhibitor, and $1 \mathrm{mmol}^{-1}$ of PMSF were added freshly to one milliliter of lysis buffer. Then cells were sonicated on the ice at $20 \mathrm{kHz}$ for $5 \times 20$ s with the 40 s of cooling breaks off. The supernatant was collected by centrifugation at $1000 \times \mathrm{g}$ for 30 at $4^{\circ} \mathrm{C}$. Proteins were precipitated by TCA/ acetone precipitation method (Nandakumar et al., 2003) and the protein concentration was determined by Bradford assay using bovine serum albumin as the standard (Bradford, 1976). 


\section{Two-dimensional gel electrophoresis (2-DE)}

Isoelectric focusing (IEF) was performed using a gradient gel $(17 \mathrm{~cm}$, linear-gradient pH 3-10). $300 \mu \mathrm{g}$ of lysates were diluted with a rehydration buffer (8 $\mathrm{mol} \mathrm{I}^{-1}$ Urea, 4\% CHAPS, 0.2\% Biolyte 3/10, 0.0002\% Bromophenol Blue and $50 \mathrm{mmol} \mathrm{I}^{-1} \mathrm{DTT}$ ) to $300 \mu \mathrm{l}$. The samples were loaded onto the immobilized pH gradient strips, $17 \mathrm{~cm}$, pH 3-10(Bio-Rad Laboratories). Following the rehydration passively for $16 \mathrm{~h}$ at $25^{\circ} \mathrm{C}$, Isoelectrofocusing (IEF) was performed using the PROTEAN $®$ IEF Cell System (Bio-Rad Laboratories) for a total of $50 \mathrm{kVh}$ at $20^{\circ} \mathrm{C}$. For the second dimension, the rehydrated IPG strips were equilibrated in equilibration buffer 1 (6 mmol I-1 urea, 2\% SDS, 20\% glycerol, 0.05M Tris-HCl, and 2\% DTT) and equilibration buffer 2 (6 $\mathrm{mmol} \mathrm{I}^{-1}$ urea, $2 \%$ SDS, $20 \%$ glycerol, $0.05 \mathrm{~mol} \mathrm{I}^{-1}$ Tris- $\mathrm{HCl}$, and $2.5 \%$ lodoacetamide) each for 20 min. The second-dimensional separation was performed on $12 \%$ sodium dodecyl sulfate-polyacrylamide gel electrophoresis (SDS-PAGE) gels, and electrophoresis was performed at 16 mA/gel for 30 min followed by 24 mA/gel for 5h, using PROTEAN® II xi electrophoresis cell (Bio-Rad Laboratories, Hercules, CA, USA).

For protein spot visualization, the gels were stained with the silver nitrate method. The analysis of gel images was performed using Image Master 2DPlatinum software (GE Healthcare, USA) followed by scanning at a resolution of $300 \mathrm{dpi}$ via densitometer GS-800(Bio-Rad, USA). Statistical analysis of protein differences was carried out using the t-test with $p<0.05$ on \% volume of matched spots with CV\% of less than 40 for each spot.

\section{Mass spectrometry analysis}

Protein spots were manually cut from 2-DE gels and dried completely. Silver dye was removed from gel pieces by Farmer's reagent (15 mM potassium ferricyanide/50 M sodium thiosulphate). Gel spots were covered by Farmer's reagent and left at room temperature for 10 min until the gels go clear, then the supernatant was removed. The Ettan Spot Handling Workstation

(GE Healthcare, UK) is used for automatic in-gel digestion of samples. Each silver removed gel plug was soaked in $100 \mathrm{mM}$ ammonium bicarbonate for $1 \mathrm{~h}$ and washed twice in $50 \% \mathrm{ACN} / 100 \mathrm{mM}$ ammonium bicarbonate. The gel pieces were then dehydrated by incubation with $0.1 \mathrm{~mL}$ ACN for 10 min. Samples then were re-hydrated by the addition of freshly prepared trypsin solution $\left(0.5 \mu \mathrm{g}\right.$ modified porcine trypsin in $\left.25 \mu \mathrm{L} 20 \mathrm{mM} \mathrm{NH}_{4} \mathrm{HCO}_{3}\right)$ and incubated for $240 \mathrm{~min}$ at $37^{\circ} \mathrm{C}$.

Peptides were extracted from the gel plugs, by washing twice in $100 \mu \mathrm{L}$ of $50 \% \mathrm{ACN}, 0.1 \%$ trifluoroacetic acid (TFA), and transferred in solution to a fresh 96 well plate, where samples were dried. Tryptic peptides were resuspended in $3 \mu \mathrm{L}$ of $50 \% \mathrm{ACN}, 0.1 \% \mathrm{TFA}$. $0.3 \mu \mathrm{L}$ of resuspended tryptic peptides were spotted onto a steel Applied Biosystems 192 sample MALDI target plate, and mixed (while wet) with $0.3 \mu \mathrm{L}$ of a $90 \%$ saturated $\mathrm{CHCA}$ in $50 \%$ ACN, $0.1 \%$ TFA. The dried samples were analyzed using a MALDI-TOF/TOF MS (4700 Proteomics Analyzers, Applied Biosystems, UK), performing MS analysis and subsequent MS/MS analysis on up to 10 precursor peptides. Each sample was internally calibrated by reference to specific autolytic fragments of trypsin. The PMF and MS/MS information were automatically searched against the NCBI mouse database using the Mascot search engine (Matrix Science, UK). Mass tolerance settings of 1.2 Da for parent ion and 0.5 Da for fragment ions were applied. Search settings allowed one missed cleavage with trypsin and two modifications (carboxamidomethylation of cysteine and oxidation of methionine). Statistical confidence limits of $95 \%$ were applied for protein identification.

\section{Results}

\section{Effects of stress conditions on the growth of $R$. planticola}

Cell viability of $R$. planticola cells exposed to different stresses as shown in Fig. 1(A-D). As shown, increasing the severity of all stress conditions (acid alkaline, heat, oxidative, and osmotic pressure) reduced viable counts (CFU/ml) of $R$. planticola cells compared to the non -stress conditions. Shifting temperature from $37^{\circ} \mathrm{C}$ to $45^{\circ} \mathrm{C}$ decreased logarithm colony forming unit per milliliter (CFU/ml) of $R$. planticola about 1.39 fold, no bacterial growth was observed above $85^{\circ} \mathrm{C}$. Sodium chloride at a concentration of $14 \%(\mathrm{w} / \mathrm{v})$ inhibited the growth of $R$. planticola, completely. Hydrogen peroxide at a sublethal concentration of 4000 ppm decreased about 7.62 fold in $\mathrm{CFU} / \mathrm{ml}$ of cell viable count, and pH maximum reduction in viable cell formation of $R$. planticola cells was observed at $\mathrm{pH}$ 3.0. The effect of each stress condition on the growth parameters of $R$. planticola is shown in Table1. Under normal growth conditions, we observed that cells reach the stationary plateau at $\left(\mathrm{OD}_{600}=1.30\right)$. Upon increasing each stress parameter including temperature, $\mathrm{NaCl}$ concentration, and oxidative stress $\left(\mathrm{H}_{2} \mathrm{O}_{2}\right)$ decreasing of optimal cell density of R.planticola cells were observed as shown in Table 1. In the case of alkaline and acidic stress conditions, optimal growth of R.planticola observed at pH 7.0.0ther growth parameters such as specific rate $(\mu)$ and doubling time follow the same pattern, which is indicated above, also shown in Table 1.

\section{Proteome analysis of oxidative stress on $R$. planticola}

Amongst all stress conditions, $\mathrm{H}_{2} \mathrm{O}_{2}$ at $4000 \mathrm{ppm}$ concentration had significant effects on $R$. planticola cells. So, this condition was selected for proteomics analysis. The results of two- dimensional gel electrophoresis (2-DE) are presented in Fig. $2 \mathrm{~A}$ and $2 \mathrm{~B}$. Approximately 1400 spots were identified in two-dimensional gel electrophoresis (2-DE). Among the identified spots, 85 spots were repeatable using 2D-Platinum software via densitometer GS-800, and eye confirmation. Amongst the repeatable spots, 9 spots showed a statistically significant difference in expression level (more than 1.2 fold) using T-student analysis. The statistically significant spots were labeled on the 2D gel as shown in Fig. 2A and B. Six proteins were successfully identified through MALDI-TOF-MS analysis and MASCOT searching in the NCBI database. 
Each protein's spot number, protein name, experimental and theoretical pl, and molecular weight, mascot score, percentage of sequence coverage, accession number, and the fold change in expression for the six identified proteins are given in Table 2. The identified proteins were 2,3-

dihydroxybenzoate-2,3-dehydrogenase (oxidoreductase family), Hypothetical Protein G787-04832 (Escherichia coli HVH 127), D-galactose-binding periplasmic protein, uridine phosphorylase (glycosyltransferases ), and a single peptide match to cystine-binding periplasmic protein and NADP(H) nitroreductase, respectively. All these identified proteins showed decreased level expression in comparison to the controls. Comparison of twodimensional gel electrophoresis of six identified differently expressed protein spots are presented in Fig. 3. As shown, all six identified protein spots:1(30666), 2(29202), 3(30260), 5(30561), 6(30627), and 7(31093) showed down-regulated expression pattern. The histogram chart for each protein spot is shown on the right side of each spot (Fig. 3$)$. All data are mean $\pm S D(p<0.05)$ of triple determinations according to the t-test.

Table 1. Comparison of the growth rate, doubling time of exponential phase, and maximum optimal density of R.planticola PTCC 1598 culture after 16 hours of growth. Values are mean $\pm S D$ of triple determinations. 


\begin{tabular}{|c|c|c|c|}
\hline Stress condition & Specific growth rate $\left(\mathrm{h}^{-1}\right)$ & Doubling time $(\mathrm{h})$ & $\begin{array}{l}\text { Maxiumm } \\
\text { OD at } \\
600 \mathrm{~nm}\end{array}$ \\
\hline \multicolumn{4}{|l|}{ Temperature ${ }^{\circ} \mathrm{C}$} \\
\hline 37 & $0.84 \pm 0.011$ & $0.83 \pm 0.016$ & 1.28 \\
\hline 45 & $0.43 \pm 0.007$ & $1.13 \pm 0.024$ & 1.03 \\
\hline 55 & $0.29 \pm 0.003$ & $1.83 \pm 0.015$ & 0.67 \\
\hline 65 & $0.21 \pm 0.015$ & $2.21 \pm 0.022$ & 0.36 \\
\hline 75 & $0.13 \pm 0.008$ & $3.08 \pm 0.181$ & 0.15 \\
\hline \multicolumn{4}{|l|}{$\mathrm{NaCl} \%(\mathrm{~W} / \mathrm{V})$} \\
\hline 2 & $0.79 \pm 0.005$ & $0.88 \pm 0.028$ & 1.17 \\
\hline 4 & $0.64 \pm 0.012$ & $0.96 \pm 0.036$ & 1.09 \\
\hline 6 & $0.56 \pm 0.006$ & $1.09 \pm 0.021$ & 0.87 \\
\hline 8 & $0.43 \pm 0.005$ & $1.23 \pm 0.126$ & 0.55 \\
\hline 10 & $0.36 \pm 0.017$ & $1.69 \pm 0.221$ & 0.46 \\
\hline 12 & $0.23 \pm 0.009$ & $2.35 \pm 0.181$ & 0.15 \\
\hline 14 & $0.18 \pm 0.012$ & $2.97 \pm 0.217$ & 0.09 \\
\hline \multicolumn{4}{|l|}{$\mathrm{H}_{2} \mathrm{O}_{2}($ PPM) } \\
\hline 500 & $0.68 \pm 0.006$ & $1.31 \pm 0.019$ & 1.22 \\
\hline 1000 & $0.47 \pm 0.017$ & $1.79 \pm 0.022$ & 1.03 \\
\hline 2000 & $0.25 \pm 0.009$ & $2.67 \pm 0.141$ & 0.77 \\
\hline 4000 & $0.05 \pm 0.004$ & $3.38 \pm 0.091$ & 0.10 \\
\hline \multicolumn{4}{|l|}{$\mathrm{pH}$} \\
\hline 3 & $0.11 \pm 0.013$ & $2.49 \pm 0.131$ & 0.12 \\
\hline 4 & $0.18 \pm 0.019$ & $1.96 \pm 0.081$ & 0.34 \\
\hline 5 & $0.32 \pm 0.010$ & $1.21 \pm 0.210$ & 0.58 \\
\hline 6 & $0.63 \pm 0.009$ & $0.98 \pm 0.028$ & 0.76 \\
\hline 7 & $0.88 \pm 0.007$ & $0.88 \pm 0.018$ & 1.31 \\
\hline 8 & $0.73 \pm 0.016$ & $1.12 \pm 0.032$ & 1.21 \\
\hline 9 & $0.56 \pm 0.006$ & $1.71 \pm 0.101$ & 0.78 \\
\hline 12 & $0.31 \pm 0.012$ & $2.13 \pm 0.212$ & 0.63 \\
\hline
\end{tabular}

Table 2. The list of identified proteins differently expressed in R. planticola PTCC 1598 upon exposure to $\mathrm{H}_{2} \mathrm{O}_{2}$ 


\begin{tabular}{|c|c|c|c|c|c|c|c|}
\hline $\begin{array}{l}\text { Spot No. } \\
\text { (code) }\end{array}$ & Protein Name & $\begin{array}{l}p l \\
\text { observed/ } \\
\text { calculated }\end{array}$ & $\begin{array}{l}\text { Mw (kDa) } \\
\text { observed/calculated }\end{array}$ & $\begin{array}{l}\text { Accession } \\
\text { number } \\
(\mathrm{NCBI})\end{array}$ & $\begin{array}{l}\text { Mascot } \\
\text { score }\end{array}$ & $\% \mathrm{SC}$ & $\begin{array}{l}\text { Protein } \\
\text { level } \\
\text { ratio } \\
\text { (fold } \\
\text { change) }\end{array}$ \\
\hline $1(30666)$ & 2,3 dihydroxybenzoate-2,3-dehydrogenase & $5.4 / 5.6$ & $26.438 / 26.35$ & $\begin{array}{l}\text { WP- } \\
004859369\end{array}$ & 164 & 17 & 1.9 \\
\hline $2(29202)$ & $\begin{array}{l}\text { Hypothetical Protein G787-04832 (Escherichia } \\
\text { coli HVH 127) }\end{array}$ & $6.85 / 7.05$ & $18.455 / 18.24$ & EQR47256 & 42 & 5 & 1.5 \\
\hline $3(30260)$ & D-galactose-binding periplasmic protein & $6.73 / 6.92$ & $36.912 / 36.94$ & EEW43536 & 117 & 6 & 1.5 \\
\hline \multirow[t]{2}{*}{$5(30561)$} & Uridine phosphorylase & & & & & & \\
\hline & (Enterobacteriaceae and Raoltella spp.) & $5.68 / 5.89$ & $27.243 / 27.09$ & $\begin{array}{l}\text { WP- } \\
004869655\end{array}$ & 631 & 40 & 1.3 \\
\hline $6(30627)$ & $\begin{array}{l}\text { Single peptide match to cystine-binding } \\
\text { periplasmic protein }\end{array}$ & $5.83 / 6.21$ & $31.49 / 31.07$ & EFI85938 & 63 & 4 & 1.4 \\
\hline 7(31093) & $\mathrm{NADP}(\mathrm{H})$ nitroreductase & $6.34 / 6.74$ & $20.150 / 20.00$ & $\begin{array}{l}\text { WP- } \\
004860825\end{array}$ & 125 & 14 & 1.2 \\
\hline
\end{tabular}

\section{Discussion}

Recently, Raoultella spp. have been identified as important emerging pathogens and should be completely considered. $R$. planticola have similar pathogenetic features as Klebsiella species, especially in hospitalized and immunocompromised patients, and have been estimated to cause between $3 \%$ to $\%$ of all nosocomial infections(Cho et al., 2016; Fager \& Yurteri-Kaplan, 2019).

Between 2015 till 2019, about 50\% of R. planticola infections were UTIs and, cystitis is the most common type of infection. Following a burn injury, $R$. Planticola was revealed in a case of bacteremia-induced fatal septic shock(Fager \& Yurteri-Kaplan, 2019).

Westerveld et al. 2017 reported the third case of $R$. planticola pneumonia in an immunocompromised patient with no history of attributable environmental exposure risks. So, with increasing reports concerning $R$. planticola, in the future, it can be considered a more prevalent pathogen in the health care setting. Although according to the recent reports $R$. planticola remains widely susceptible to many antibiotics, another problem is the emerging of antibiotic-resistant strains causing significant mortality (Westerveld et al., 2017). Due to the above reasons, studies regarding better understandings of the mechanisms by which R.planticola responds to different stress conditions could be useful to prevent infections by this bacterium in health care systems. Any change in the surrounding conditions including different stresses would affect the physiological response given by the bacterial cells.

In this study, we evaluated the effect of a variety of stress conditions on cell growth of $R$. planticola PTCC 1598. Comparing cell growth parameters, we observed reaching the exponential phase for $16 \mathrm{~h}$ in control and stress conditions. Cells grown on control nutrient broth medium have a doubling time (td) around 0.9 (h), whereas cells were grown on stress conditions certain increase in doubling time was observed. Maximum doubling time (td) of 3.38 (h) was observed upon oxidative stress containing sublethal concentration (4000ppm) of $\mathrm{H}_{2} \mathrm{O}_{2}$. Thus, changing growth parameters could be reflected in protein expression patterns of $R$. planticola under different stress conditions. According to the obtained results, a proteomic analysis was carried out to investigate the oxidative stress response of this bacterium at a sublethal concentration of $\mathrm{H}_{2} \mathrm{O}_{2}(4000 \mathrm{ppm})$. Based on the obtained results, six successfully identified proteins that showed acceptable levels in expression were downregulated. The first identified proteins (spot1,30666) is 2, 3-dihydroxybenzoate-2, 3-dehydrogenase (EntA), belongs to the genus Raoultella which also has been identified in Raoultella ornithinolytica strains. This enzyme catalysis the chemical reaction of 2,3-dihydro-2,3- dihydroxybenzoate and NAD ${ }^{+}$to $2,3-$ dihydroxybenzoate $\mathrm{NADH}^{+}$

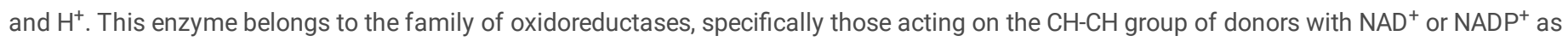
acceptor, and participates in the biosynthesis of siderophore group such as enterobactin (Khalil \& Pawelek, 2011; Young \& Gibson, 1969). Enterobactin biosynthesis occurs through the activity of six enzymes. EntC, EntB, and 2, 3-dihydroxybenzoate-2, 3-dehydrogenase (entA) catalyze the conversion of chorismate into dihydrobenzoic acid. Then, entD, entE, entB, and entF act to condense the three molecules each of DHB and L-serine into one enterobactin molecules(Khalil \& Pawelek, 2011). According to a study performed by Holden et al. 2016, Klebsiella pneumoniae requires secretion of 
siderophores, for bacterial replication and full virulence. The combination of siderophores secreted by $K$. pneumoniae during infection can affect tissue localization, systemic dissemination, and host survival(Holden et al., 2016).

It seems that $R$. planticola strains to cause human infections siderophore secretions play an important role in pathogenesis, and suppressing the genes encoding the key enzymes of the metabolic route leads to decreasing pathogenesis of the bacterium. In our proteomics analysis, expression of 2, 3-dihydroxybenzoate-2, 3-dehydrogenase (entA) decreased upon exposure to oxidative stress which, could reduce the pathogenicity of R.planticola.

The second protein (spot.2, 29202) is a hypothetical protein G787-04832, which has been identified in Escherichia coli HVH 127, and Klebsiella oxytoca MGH 42 strains. According to surveys, studies have not shown a specific role for this protein in E.coli and Klebsiella genera. Also, we could identify this hypothetical protein in the genus R.planticola.

The third protein (spot.3,30260) is a periplasmic D-galactose-binding protein was identified, which has been reported in K. pneumoniae subsp. rhinoscleromatis ATCC 13884. This protein encodes by the $m g / B$ gene, and its functions are chemotaxis and sugar transport. So, decreasing the expression level of this protein can impair sugar transportation, and causes nutrient deficiencies in R.planticola. In this study, oxidative stress could reduce the expression of this protein. The fourth identified protein (spot.5, 30561) is a uridine phosphorylase, which has been specifically identified in Raoultella spp. Uridine phosphorylase belongs to the family of glycosyltransferases, specifically the pentosyltransferases, which catalysis the formation of uracil and alpha-D-ribose 1-phosphate from uridine substrate. This enzyme participates in pyrimidine metabolism. Pyrimidines are essential biomolecules and are structural components of nucleotides, nucleic acids, and vitamins. Also, pyrimidines can be degraded to simple metabolites, which become the source of carbon and nitrogen(Garavito et al., 2015).

Decreased uridine phosphorylase activity can stop the synthesis of pyrimidine bases, and all related metabolic pathways to pyrimidines in $R$. planticola. This can be very harmful to bacterial growth and multiplication. In our study sublethal concentration of $\mathrm{H}_{2} \mathrm{O}_{2}$ could significantly decrease uridine phosphorylase activity in proteome analysis.

According to the NCBI database, the fifth identified protein (spot 6, 30627) is a cystine binding periplasmic protein found in E.coli MS 196 . This protein catalyzes the transport of cystine into the cytoplasm. The Inducible L-cysteine/L-cystine shuttle system plays an important role in detoxifying hydrogen peroxide before lipid peroxidation occurs(Ohtsu et al., 2015).

Since catalase does not occur in the periplasm, the $\mathrm{H}_{2} \mathrm{O}_{2}$ generated by the electron transport chain in the inner membrane is detoxified by this shuttle system. Thus, we assume, like $E$. coli, cystine periplasmic protein has a similar role in the detoxification of $\mathrm{H}_{2} \mathrm{O}_{2}$ generated by $R$ planticola cells. Upon stress condition and inactivation of this protein, cytotoxic reactive oxygen species (ROS) destroys DNA, proteins, and cellular membrane lipids.

$\operatorname{NADP}(\mathrm{H})$ nitroreductase was the last identified protein (spot 7, 31093) in our oxidative stress condition. This protein belongs to Raoultella and Klebsiella spp. Three NADP(H)-dependent nitroreductases can transform 2,4,6-trinitrotoluene (TNT) by two reduction pathways were detected in Klebsiella sp. C1 by(Kim \& Song, 2005). Nitroaromatic compounds are the most widely used compounds in pharmaceuticals, explosive, and agrochemical industries.

Nitroaromatic compounds are recalcitrance, and we should prevent the accumulation of these compounds in manufacturing areas(Kim \& Song, 2005). In environmental biotechnology, the biodegradation of nitroaromatic compounds such as 2,4,6-trinitrotoluene (TNT) is one of the potential uses of Klebsiella spp. We assume that R. planticola has the ability to degrade nitroaromatic compounds as well as Klebsiella spp. But in oxidative stress conditions, this ability may reduce. According to our study, there is not much information about the effect of environmental stresses and proteomics study on $R$. planticola to compare. In the case of a related genus, a proteomic analysis on Klebsiella oxytoca after exposure to succinonitrile was reported(Tang et al., 2008). Succinonitrile is an environmental pollutant, which its degradation has been shown by $K$.oxytoca. The growth rate of K.oxytoca was decreased upon exposure to succinonitrile. They could identify 7 differently expressed proteins in K.oxytoca treated with succinonitrile in comparison to the cells treated with ammonia. Expression of superoxide dismutase (SOD), glutathione-S-transferase (GST), and PsaA, a metal-binding protein was increased upon treatment of succinonitrile, which suggests that biodegradation of succinonitrile was accompanied by the occurrence of oxidative stress(Tang et al., 2008).

So, the ability of $R$. planticola for detoxifications of succinonitrile could be considered for further studies. The effect of $\mathrm{pH}$, temperature, $\mathrm{NaCl}$ concentration, and heat resistance was studied by Tantasuttikul and Mahakarnchanakul (2019) on R. ornithinolytica and $R$. terrigenous strains isolated from a seafood processing plant in Thailand. The obtained results showed that the optimum $\mathrm{pH}$, temperature, and $\mathrm{NaCl}$ concentration for growth were $6-9,15-37^{\circ} \mathrm{C}$, and $1-4.5 \%$, respectively. For heat resistance, D-values of both species gave similar results about $0.66-0.79$ min at $57^{\circ} \mathrm{C}$, with Z-values $4.2-4.5^{\circ} \mathrm{C}$. The results obtained in this study are similar to the study of Tantasuttikul and Mahakarnchanakul (2019). Optimum pH and temperature for R.planticola were $6-7$ and $37^{\circ} \mathrm{C}$, respectively. Also, R.planticola could tolerate $\mathrm{NaCl}$ concentration up to $10 \%(\mathrm{~W} / \mathrm{V})$ in nutrient broth medium.

Effects of arsenite stress on growth and proteome of Klebsiella pneumoniaewere studied by Daware et al. (2012). Arsenic is widely dispersed in natural environments such as volcanic areas, during weathering of rocks and mining as well as from anthropogenic sources, including pesticide usage, high-temperature combustion, and smelting of metals. The most oxidation states of arsenic are the pentavalent arsenate, As(V), and the trivalent arsenite, As(III). Between two, As(III) is 100 times more toxic than As(V) to living organisms. It binds to sulfhydryl groups of amino acids, thus 


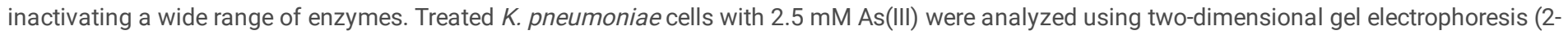
DGE) and matrix-assisted laser desorption ionization-time of flight-time of flight (MALDI-TOF/TOF). The results showed that 60 proteins were differentially expressed under As(III) stress, of which 39 proteins were successfully identified. Among 39 identified proteins, some such as outer membrane proteins down-regulated, and some including antioxidant proteins upregulated. These proteins play an important role during arsenite stress conditions. In the present study, six identified proteins were down-regulated, including those incorporated into sugar transport, siderophore, and pyrimidine biosynthesis. The impaired expression of proteins can cause metabolic defects and growth retardation in R.planticola cells upon exposure to hydrogen peroxide. Based on the obtained results in this study, and due to increasing reports of R.planticola infections, there is a need to find the best ways to prevent its spread, especially in health care systems. From a medical standpoint, hydrogen peroxide has been used as a disinfectant, due to its cheap cost and widespread availability. $\mathrm{H}_{2} \mathrm{O}_{2}$ has activity against bacteria, viruses, and even spores. It can cause cellular damages results from the oxidation of membranes, proteins, and even DNA (Pan et al., 2019). In a study by (Van Meurs et al. 2014), $\mathrm{H}_{2} \mathrm{O}_{2}$ was found to have a minimal bactericidal concentration of 1\% against both Staphylococcus aureus and Staphylococcus epidermidis (Van Meurs et al., 2014).

Also, it has been shown that $\mathrm{H}_{2} \mathrm{O}_{2}$ shows cytotoxicity activity at concentrations as low as

$0.03-0.06 \%$. In this study, $\mathrm{H}_{2} \mathrm{O}_{2}$ at a concentration of $8000 \mathrm{ppm}(0.8 \%)$ could inhibit the growth of R.planticola cells completely. Also, in our proteomic study, using a sublethal concentration of $4000 \mathrm{ppm}(0.4 \%) \mathrm{H}_{2} \mathrm{O}_{2}$ could affect the proteome of R.planticola cells. In conclusion, based on the results obtained in this study, we recommend using an antiseptic solution containing $\mathrm{H}_{2} \mathrm{O}_{2}$ at $8000 \mathrm{ppm}(0.8 \%)$ concentration to prevent the spread of R.planticola in health care, seafood processing systems. This is especially important for the elderly and immunocompromised patients, which are at high risk and susceptible to different infectious diseases.

\section{Declarations}

\section{Funding}

This research did not receive any specific grant from funding agencies in the public, commercial, or not-for-profit sectors and the authors financially supported this work.

\section{Acknowledgements}

The laboratory facilities of microbial experiments were provided by Lahijan Branch, Islamic Azad University, Lahijan, Iran. The authors are grateful to Dr.Behrouz Vaziri and Mrs. Bahareh Azarian at Protein Chemistry Unit, Biotechnology Research Center, Pasteur Institute of Iran and ProteomicsTechnology Facility, Department of Biology, the University of York UK for their helpful assistance in proteomics analysis.

\section{Author contribution}

This study was performed based on a master of science (MSc) thesis addressed to Zeynab Hajian. ZH, MFG, and FEA contributed almost equally to this study. MFG, designed the study, ZH and FEA did the experiments and performed research; MFG analyzed all data and wrote the paper.

\section{Complaince with ethical standards}

\section{Conflict of interest}

The author declares that they have no conflict of interest.

\section{References}

Baez, A., \& Shiloach, J. (2013). Escherichia coli avoids high dissolved oxygen stress by activation of SoxRS and manganese-superoxide dismutase. Microbial Cell Factories, 12(1), 23.

Bagley, S. T., Seidler, R. J., \& Brenner, D. J. (1981). Klebsiella planticola sp. nov.: a new species of Enterobacteriaceae found primarily in nonclinical environments. Current Microbiology, 6(2), 105-109.

Bartholomäus, A., Fedyunin, I., Feist, P., Sin, C., Zhang, G., Valleriani, A., \& Ignatova, Z. (2016). Bacteria differently regulate mRNA abundance to specifically respond to various stresses. Philosophical Transactions of the Royal Society A: Mathematical, Physical and Engineering Sciences, 374(2063), 20150069.

Bradford, M. M. (1976). A rapid and sensitive method for the quantitation of microgram quantities of protein utilizing the principle of protein-dye binding. Analytical biochemistry, 72(1-2), 248-254.

Cho, Y. J., Jung, E. J., Seong, J. S., Woo, Y. M., Jeong, B. J., Kang, Y. M., \& Lee, E. (2016). A case of pneumonia caused by Raoultella planticola. Tuberculosis and respiratory diseases, 79(1), 42-45. 
Daware, V., Kesavan, S., Patil, R., Natu, A., Kumar, A., Kulkarni, M., \& Gade, W. (2012). Effects of arsenite stress on growth and proteome of Klebsiella pneumoniae. Journal of biotechnology, 158(1-2), 8-16.

Fager, C., \& Yurteri-Kaplan, L. (2019). Urinary tract infection with rare pathogen Raoultella Planticola: A post-operative case and review. Urology case reports, $22,76$.

Garavito, M. F., Narváez-Ortiz, H. Y., \& Zimmermann, B. H. (2015). Pyrimidine metabolism: dynamic and versatile pathways in pathogens and cellular development. Journal of genetics and genomics, 42(5), 195-205.

Guo, M. S., \& Gross, C. A. (2014). Stress-induced remodeling of the bacterial proteome. Current Biology, 24(10), R424-R434.

Hayyan, M., Hashim, M. A., \& AlNashef, I. M. (2016). Superoxide ion: generation and chemical implications. Chemical reviews, $116(5), 3029-3085$.

Holden, V. I., Breen, P., Houle, S., Dozois, C. M., \& Bachman, M. A. (2016). Klebsiella pneumoniae siderophores induce inflammation, bacterial dissemination, and HIF-1a stabilization during pneumonia. MBio, 7(5).

Khalil, S., \& Pawelek, P. D. (2011). Enzymatic Adenylation of 2, 3-Dihydroxybenzoate Is Enhanced by a Protein- Protein Interaction between Escherichia coli 2, 3-Dihydro-2, 3-dihydroxybenzoate Dehydrogenase (EntA) and 2, 3-Dihydroxybenzoate-AMP Ligase (EntE). Biochemistry, 50(4), $533-545$.

Kim, H.-Y., \& Song, H.-G. (2005). Purification and characterization of NAD (P) H-dependent nitroreductase I from Klebsiella sp. C1 and enzymatic transformation of 2, 4, 6-trinitrotoluene. Applied microbiology and biotechnology, 68(6), 766-773.

Lam, P. W., \& Salit, I. E. (2014). Raoultella planticola bacteremia following consumption of seafood. Canadian Journal of Infectious Diseases and Medical Microbiology, 25.

Liu, X., Sun, X., Wu, Y., Xie, C., Zhang, W., Wang, D., . . Chen, H. (2013). Oxidation-sensing regulator AbfR regulates oxidative stress responses, bacterial aggregation, and biofilm formation in Staphylococcus epidermidis. Journal of biological chemistry, 288(6), 3739-3752.

McDonnell, G. (2009). The use of hydrogen peroxide for disinfection and sterilization applications. PATAl'S Chemistry of Functional Groups, 1-34.

Montero, I. G., Dolata, K. M., Schlüter, R., Malherbe, G., Sievers, S., Zühlke, D., . . Robinson, C. (2019). Comparative proteome analysis in an Escherichia coli CyDisCo strain identifies stress responses related to protein production, oxidative stress and accumulation of misfolded protein. Microbial Cell Factories, 18(1), 1-15.

Nandakumar, M., Shen, J., Raman, B., \& Marten, M. R. (2003). Solubilization of trichloroacetic acid (TCA) precipitated microbial proteins via NaOH for two-dimensional electrophoresis. Journal of proteome research, 2(1), 89-93.

Nathan, C., \& Ding, A. (2010). SnapShot: reactive oxygen intermediates (ROI). Cell, 140(6), 951-951. e952.

Niedergethmann, M., Alves, F., Neff, J., Heidrich, B., Aramin, N., Li, L., . . Post, S. (2007). Gene expression profiling of liver metastases and tumour invasion in pancreatic cancer using an orthotopic SCID mouse model. British journal of cancer, 97(10), 1432-1440.

O'Connell, K., Kelly, J., \& NiRiain, U. (2010). A rare case of soft-tissue infection caused by Raoultella planticola. Case Reports in Medicine, 2010.

Ohtsu, I., Kawano, Y., Suzuki, M., Morigasaki, S., Saiki, K., Yamazaki, S., . . Takagi, H. (2015). Uptake of L-cystine via an ABC transporter contributes defense of oxidative stress in the L-cystine export-dependent manner in Escherichia coli. PLoS One, 10(4), e0120619.

Olson, D., Asare, K., Lyons, M., \& Hofinger, D. (2013). A novel case of Raoultella planticola urinary tract infection. Infection, 41(1), $259-261$.

Pan, S., Rodriguez, D., Thirumavalavan, N., Gross, M. S., Eid, J. F., Mulcahy, J., \& Munarriz, R. (2019). The use of antiseptic solutions in the prevention and management of penile prosthesis infections: a review of the cytotoxic and microbiological effects of common irrigation solutions. The Journal of Sexual Medicine, 16(6), 781-790.

Siauciunaite, R., Foulkes, N. S., Calabrò, V., \& Vallone, D. (2019). Evolution shapes the gene expression response to oxidative stress. International journal of molecular sciences, 20(12), 3040.

Tang, P., Liu, J.-K., Chou, S.-M., Hor, L.-I., Chen, W.-J., \& Chen, S. C. (2008). A proteomic analysis of Klebsiella oxytoca after exposure to succinonitrile. Process Biochemistry, 43(7), 753-757.

Tantasuttikul, A., \& Mahakarnchanakul, W. (2019). Growth parameters and sanitizer resistance of Raoultella ornithinolytica and Raoultella terrigena isolated from seafood processing plant. Cogent Food \& Agriculture, 5(1), 1569830.

Van Meurs, S., Gawlitta, D., Heemstra, K., Poolman, R., Vogely, H., \& Kruyt, M. (2014). Selection of an optimal antiseptic solution for intraoperative irrigation: an in vitro study. JBJS, 96(4), 285-291.

Page 10/13 
Westerveld, D., Hussain, J., Aljaafareh, A., \& Ataya, A. (2017). A rare case of Raoultella planticola pneumonia: an emerging pathogen. Respiratory medicine case reports, 21, 69-70.

Young, I., \& Gibson, F. (1969). Regulation of the enzymes involved in the biosynthesis of 2, 3-dihydroxybenzoic acid in Aerobacter aerogenes and Escherichia coli. Biochimica et Biophysica Acta (BBA)-General Subjects, 177(3), 401-411.

\section{Figures}

A

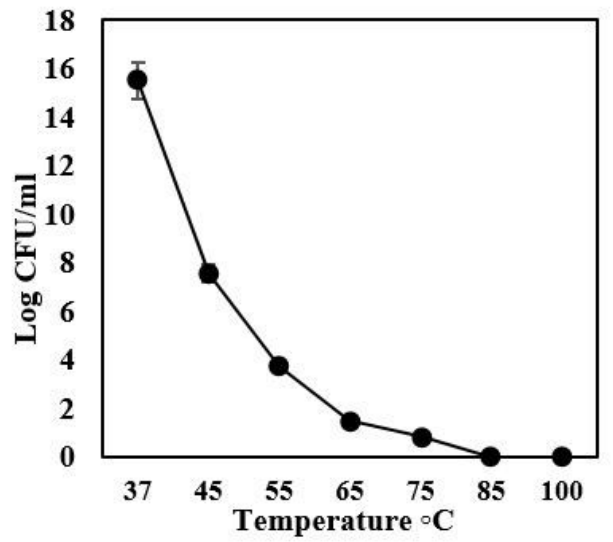

C

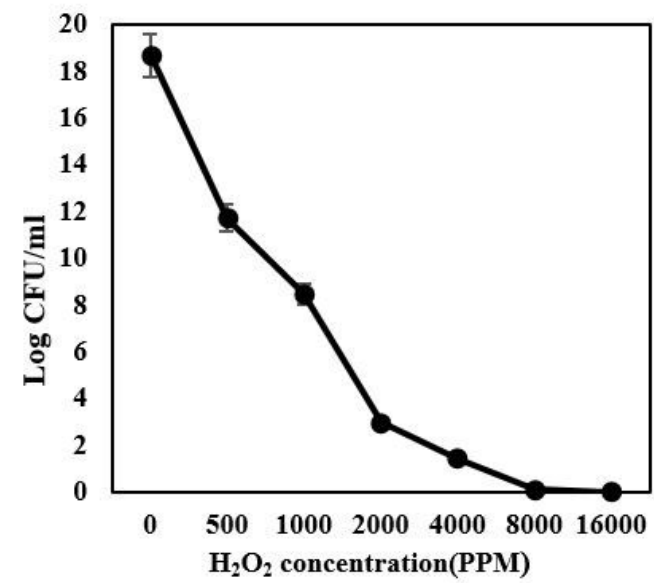

B

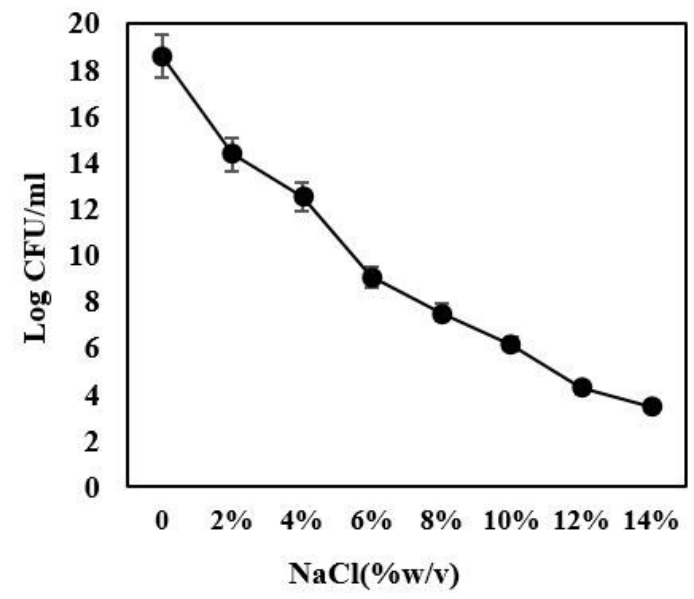

D

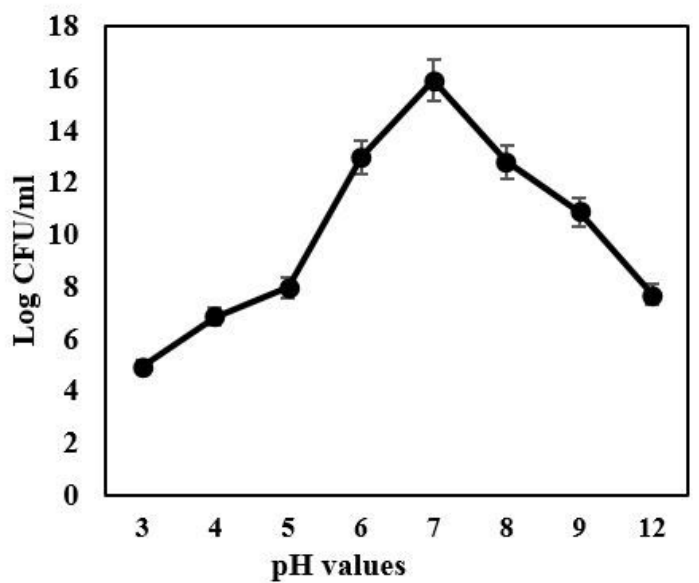

Figure 1

Viable cells counts (Log10) of R. planticola PTCC 1598 upon exposure to different stress conditions (A, temperature , B,osmotic NaCl, C, oxidative $\mathrm{H} 2 \mathrm{O} 2$ and $\mathrm{D}, \mathrm{pH})$.Values are mean $\pm \mathrm{SD}$ of triple determinations 

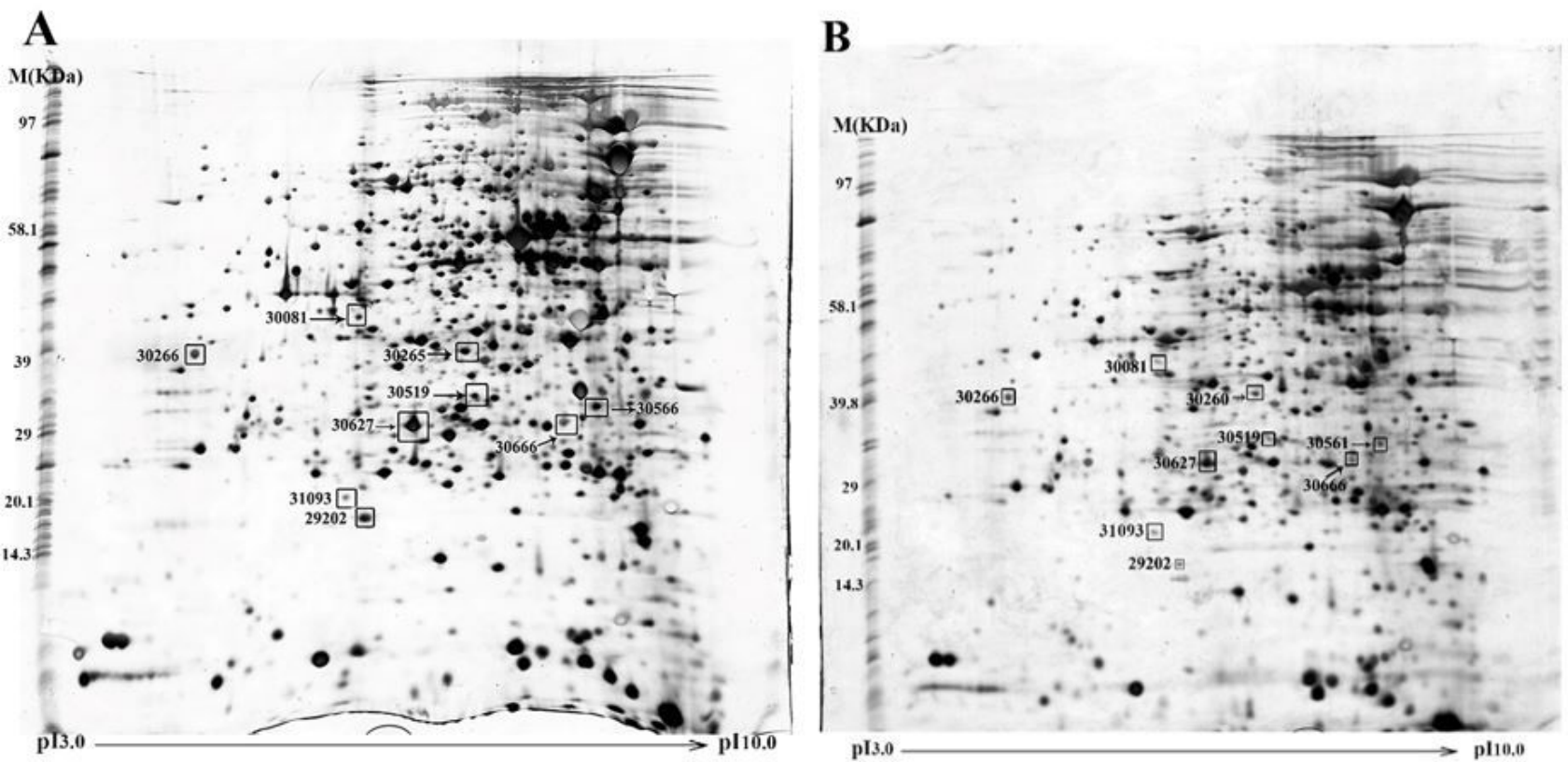

Figure 2

Two-dimensional gel electrophoresis of cell extract proteins of R. planticola PTCC 1598 cells grown in nutrient broth medium control (A) and in presence of 4000 ppm H2O2 (B). The identified protein spots indicated by arrows.

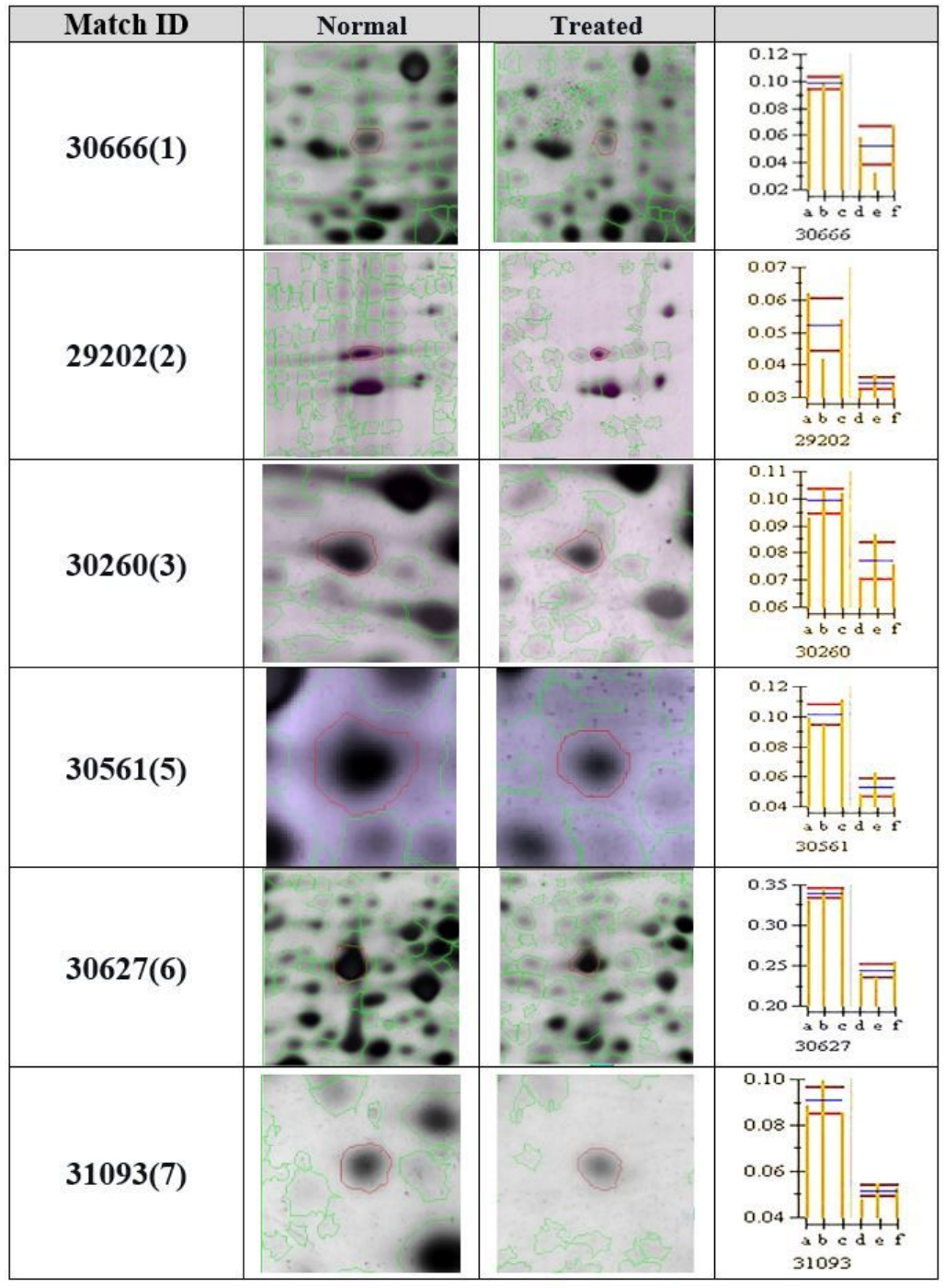




\section{Figure 3}

Comparison of 2D gel electrophoresis between six identified differently expressed protein spots of R. planticola PTCC 1598 in non stressed and stressed conditions (4000 ppm H2O2). The spots are 1(30666), 2(29202), 3(30260), 5(30561), 6(30627), and 7(31093) according to the Table 2. Comparison of six protein levels determined by image master 2D-platinum software. Bars represent mean $\pm S D, p<0.05$ of triple determinations. 